\title{
Paraplegia
}

\section{Social Role Functioning Following Spinal Cord Injury}

\author{
M. Stambrook, PhD, C Psych, S. MacBeath, BA (Hons), A. D. Moore, MA, \\ L. C. Peters, PhD, E. Zubek, I. C. Friesen, BA (Hons) \\ Departments of Medicine, Psychiatry, and Psychology University of Manitoba, Society \\ for Manitobans with Disabilities, and Neuropsychology Research Unit, Health Sciences \\ Clinical Research Centre, Manitoba, Winnipeg, Canada.
}

\begin{abstract}
Summary
The Katz Adjustment Scale-Relatives Form was completed by the wives of 27 hospital-discharged spinal cord injured (SCI) patients. Their ratings of the spouses' social adjustment and behaviour were compared to available community and psychiatric norms. Overall, spouses rated their SCI husbands as performing significantly more socially inappropriate behaviours compared to ratings of 'normals' but as engaging in significantly less socially inappropriate behaviours compared to the ratings of psychiatric patients. SCI patients were perceived as performing the same levels of social activities as 'normals', but engaging in less free-time activities compared to both 'normals' and psychiatric patients. These results mirror similar analyses comparing moderate and severe head injury victims with normal and psychiatric norms. The implications for rehabilitation and counselling of families of traumatically disabled patients are discussed. Key words: Social adjustment; Social behaviour; Spinal cord injury.
\end{abstract}

Individuals with a spinal cord injury (SCI) must face considerable adjustment in their lives as they cope with the long term consequences of their disability (Cook, 1979; Woodbury, 1978). Research here has focused on the patients' adjustment following SCI, including issues such as income level and employment, independence in activities of daily living, psychological adjustment, and the quality of social relationships. However, these studies, for the most part, have relied on patient self-report measures and have not attempted to incorporate the spouse's perspective on patient adjustment.

Correspondence and reprint requests to: Dr M. Stambrook, Neuropsychology Research Unit, RR-435, Health Sciences Centre, 800 Sherbrook Street, Winnipeg, Manitoba, Canada, R3A 1M3.

An earlier version of this paper was presented at the Canadian Psychological Association Meetings in Halifax, Nova Scotia, Canada, June 1989. This research was supported by the Manitoba Health Research Council, the Manitoba Mental Health Research Foundation, and the Medical Research Council of Canada. 
Several researchers have, however, recently suggested that social support from significant others may be an important factor in determining adjustment to SCI (Barnes et al. 1987; Bracken and Shepard, 1980). More specifically, it has been found that a strong social network, as defined by the presence of one or more confidants, was one of the most significant correlates of post-SCI employment status (MacKenzie et al., 1987). The degree of social interaction was a critical variable in the emotional and social adjustment of both paraplegic and quadraplegic individuals (MacKelprang and Hepworth, 1987). Furthermore, marital status (DeJong, et al., 1984) and a positive family environment (McGowan and Roth, 1987) have been powerful predictors of independent functional living outcome variables, such as in home activities and social interaction.

More specifically, McGowan and Roth (1987) found the SCI subjects who perceived their family environment as affectionately responsive, open in communication, and clear in delineation of responsibility, had greater self-initiation in activities, increased social involvement, and a higher overall level of independence. Pachalski and Pachalska (1984) also demonstrated the importance of the role of the family in their research. They compared a control group of paraplegics who were treated in a rehabilitation centre to a similar group of patients whose family members played an active role in the SCI patients' rehabilitation. Results indicated that patients whose families have been involved in the rehabilitation programme, unlike the control patients, felt that their adaptation to society was either 'good' or 'very good', had increased positive self-worth, had decreased feelings of guilt and fear, were more likely to be employed, and participated in more recreational and free-time activities. These findings suggest that family members can indeed have a positive effect on the SCI patients' adjustment.

In view of the evidence indicating the positive role that the family, and the spouse in particular, can have on SCI rehabilitation, it is surprising how little research has examined the spouses' perception of their marriage relationship or their perception of the social behaviour of their SCI partner. These issues are important because the SCI patients' adjustment and social behaviour may adversely effect the quality of the marital relationship, and hence the support that the patient needs for reaching successful adjustment to the injury may be jeopardised. Although several researchers have stressed the importance of assessing the perceptions of the 'significant other' (Ernst, 1987; Malec and Nermeyer, 1982; Richards, 1986), only one study has focused on the significant other's view of their post-SCI family (McGowan and Roth, 1987). McGowan and Roth (1987) found that the duration of the disability was a good predictor of the significant others' concern of the SCI family's ability to delineate roles and maintain standards of behaviour control. The relative paucity of research in this area highlights the importance of further examining the spouses' perceptions and expectations of the SCI patients' social role functioning and behaviour.

The present paper examined wives' ratings of their SCI husbands' adjustment and social functioning, using the Katz Adjustment Scale-Relatives Form (KASR) (Hogarty and Katz, 1971). These scores were compared with KAS-R psychiatric and general norms provided by Hogarty and Katz (1971). Thus, patient social and behavioural characteristics that would most likely adversely effect positive social relationships were rated by the spouse in an attempt to determine the nature and severity of these potential problem areas. 


\section{Method}

Potential couples were identified through the records of the Spinal Cord Injury Unit at the Health Sciences Centre in Winnipeg. Twenty seven married male survivors and their spouses participated in this study. All of the participating couples met the following inclusion criteria: (1) the injured spouse was admitted to the Spinal Cord Injury Unit within the past 10 years, and (2) the couple were living together prior to the SCI and following hospital discharge. All couples completed a series of paper and pencil questionnaires, and were interviewed in a semistructured format. This paper focused on spousal responses to the KAS-R (Hogarty and Katz, 1971). Table I presents demographic and medical characteristics of the sample.

\section{Results}

A series of one-tailed t-tests were used to determine differences between KAS-R subscale scores for the current sample in comparison to the 'normal' and psychiatric samples. As the use of multiple t-tests can result in an unacceptably high rate of Type 1 error, an acceptable family-wise error rate $(p<\cdot 05)$ was preserved using the Bonferoni method. This resulted in the significant level for each of the t-tests being set at $p<\cdot 0005$.

Comparison of the SCI group with the 'normal' community sample (see Table II) demonstrated significant differences on most subscales with scores indicating that the SCI group performed more socially inappropriate behaviours than this 'normal' sample. The SCI group was rated to be significantly more belligerent, verbally expansive, negative, helpless, suspicious, anxious, withdrawn, bizarre, hyperactive, and displaying higher levels of general psychopathology compared to ratings of the 'normal' samples. There were no significant differences between ratings of the SCI group and 'normals' in the performance of social role activities and spouses' expectations of these activities. However, the SCI group engaged in significantly less recreation and free-time activities compared to the 'normals' although the SCI spouses expected significantly more free-time activities from them than did spouses from the community sample.

In contrast, SCI subjects were rated as demonstrating significantly better adjustment than were psychiatric patients (see Table III) on the negativism,

Table I Demographic and medical characteristics

\begin{tabular}{lcc}
\hline Variables & Mean & SD \\
\hline Continuous Variables & & \\
Age (years) & $44 \cdot 30$ & $15 \cdot 54$ \\
Length of initial hospital stay (days) & $125 \cdot 41$ & $51 \cdot 44$ \\
Categorical Variable & Frequency & \\
Level of Injury & 12 & \\
Cervical & 9 & \\
Thoracic & 3 & \\
Lumbar & 1 & \\
Sacral & 2 \\
Cauda Equina & \\
\hline
\end{tabular}


helplessness, suspiciousness, anxiety, withdrawal and retardation, nervousness, bizarreness, hyperactivity, and general psychopathology subscales. Although there were no differences between these groups in the spouses' expectation of social role activities, the spouse of SCI subjects expected their husbands to participate in less free-time and recreational activities and rated them as performing less of these activities than did the spouses of psychiatric patients.

Table II KAS-R SCI compared to normal population

\begin{tabular}{|c|c|c|c|c|c|}
\hline \multirow[b]{2}{*}{ KAS-R Subscale } & \multicolumn{2}{|c|}{ SCI } & \multicolumn{2}{|c|}{ Normal } & \multirow[b]{2}{*}{$t(246)$} \\
\hline & Mean & SD & Mean & SD & \\
\hline Belligerence & $5 \cdot 33$ & $1 \cdot 75$ & $4 \cdot 62$ & $0 \cdot 90$ & $3 \cdot 50^{\star}$ \\
\hline Verbal expansiveness & $7 \cdot 89$ & $3 \cdot 27$ & $5 \cdot 88$ & $1 \cdot 34$ & $7 \cdot 93^{\star}$ \\
\hline Negativism & $13 \cdot 30$ & $4 \cdot 69$ & $11 \cdot 53$ & $2 \cdot 53$ & $5 \cdot 23^{\star}$ \\
\hline Helplessness & $5 \cdot 78$ & $2 \cdot 08$ & $4 \cdot 50$ & 0.82 & $6 \cdot 43^{\star}$ \\
\hline Suspiciousness & $5 \cdot 22$ & $1 \cdot 78$ & $4 \cdot 34$ & $0 \cdot 87$ & $4 \cdot 39^{\star}$ \\
\hline Anxiety & $7 \cdot 41$ & $1 \cdot 97$ & $6 \cdot 24$ & 0.62 & $6 \cdot 57^{\star}$ \\
\hline Withdrawal and retardation & $10 \cdot 52$ & $2 \cdot 75$ & $8 \cdot 92$ & $2 \cdot 48$ & $4 \cdot 96^{\star}$ \\
\hline Psychopathology & $39 \cdot 37$ & $11 \cdot 43$ & $30 \cdot 72$ & $4 \cdot 53$ & $18 \cdot 50^{\star}$ \\
\hline Nervousness & $7 \cdot 00$ & $3 \cdot 09$ & $6 \cdot 12$ & $1 \cdot 83$ & $3 \cdot 08$ \\
\hline Confusion & $3 \cdot 11$ & $0 \cdot 42$ & $3 \cdot 13$ & 0.43 & $-0 \cdot 15$ \\
\hline Bizarreness & $6 \cdot 07$ & $1 \cdot 41$ & $5 \cdot 22$ & $0 \cdot 60$ & $5 \cdot 04^{\star}$ \\
\hline Hyperactivity & $4 \cdot 96$ & $1 \cdot 74$ & $4 \cdot 16$ & $1 \cdot 22$ & $3 \cdot 48^{\star}$ \\
\hline \multicolumn{6}{|l|}{ Social Activity } \\
\hline Performed & $38 \cdot 63$ & $4 \cdot 61$ & $38 \cdot 77$ & $4 \cdot 34$ & $-0 \cdot 33$ \\
\hline Expected & $39 \cdot 19$ & $4 \cdot 31$ & $38 \cdot 82$ & $5 \cdot 00$ & $0 \cdot 82$ \\
\hline \multicolumn{6}{|l|}{ Free-Time Activities } \\
\hline Performed & $44 \cdot 89$ & $6 \cdot 79$ & $46 \cdot 53$ & $5 \cdot 08$ & $-3 \cdot 51^{\star}$ \\
\hline Expected & $29 \cdot 89$ & $4 \cdot 11$ & $27 \cdot 03$ & $5 \cdot 08$ & $6 \cdot 29^{\star}$ \\
\hline
\end{tabular}

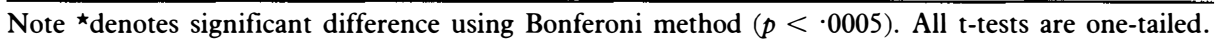

Table III KAS-R SCI compared to psychiatric population

\begin{tabular}{|c|c|c|c|c|c|}
\hline \multirow[b]{2}{*}{ KAS-R Subscale } & \multicolumn{2}{|c|}{ SCI } & \multicolumn{2}{|c|}{ Psychiatric } & \multirow[b]{2}{*}{$t(389)$} \\
\hline & Mean & SD & Mean & SD & \\
\hline Belligerence & $5 \cdot 33$ & $1 \cdot 75$ & $5 \cdot 43$ & $1 \cdot 88$ & $-0 \cdot 37$ \\
\hline Verbal expansiveness & $7 \cdot 89$ & $3 \cdot 27$ & $6 \cdot 98$ & $2 \cdot 47$ & $-2 \cdot 87$ \\
\hline Negativism & $13 \cdot 30$ & $4 \cdot 69$ & $15 \cdot 30$ & $4 \cdot 47$ & $-4 \cdot 73^{\star}$ \\
\hline Helplessness & $5 \cdot 78$ & $2 \cdot 08$ & $8 \cdot 44$ & $2 \cdot 91$ & $-7 \cdot 89^{\star}$ \\
\hline Suspiciousness & $5 \cdot 22$ & $1 \cdot 78$ & $7 \cdot 11$ & $3 \cdot 06$ & $-5 \cdot 49^{\star}$ \\
\hline Anxiety & $7 \cdot 41$ & $1 \cdot 97$ & $11 \cdot 05$ & $4 \cdot 11$ & $-9 \cdot 16^{\star}$ \\
\hline Withdrawal and retardation & $10 \cdot 52$ & $2 \cdot 75$ & $12 \cdot 29$ & $4 \cdot 10$ & $-4 \cdot 43^{\star}$ \\
\hline $\begin{array}{l}\text { Psychopathology }\end{array}$ & $39 \cdot 37$ & $11 \cdot 43$ & $46 \cdot 24$ & $10 \cdot 97$ & $-10 \cdot 38^{\star}$ \\
\hline Nervousness & $7 \cdot 00$ & 3.09 & $11 \cdot 29$ & $3 \cdot 10$ & $-12 \cdot 21^{\star}$ \\
\hline Confusion & $3 \cdot 11$ & 0.42 & $3 \cdot 68$ & $1 \cdot 36$ & $-2 \cdot 51$ \\
\hline Bizarreness & $6 \cdot 07$ & $1 \cdot 41$ & $7 \cdot 25$ & $2 \cdot 51$ & $-3 \cdot 79^{\star}$ \\
\hline Hyperactivity & $4 \cdot 96$ & $1 \cdot 74$ & $6 \cdot 82$ & $2 \cdot 33$ & $-6 \cdot 16^{\star}$ \\
\hline \multicolumn{6}{|l|}{ Social Activity } \\
\hline Performed & $38 \cdot 63$ & $4 \cdot 61$ & $30 \cdot 64$ & $5 \cdot 49$ & $-17 \cdot 19^{\star}$ \\
\hline Expected & $39 \cdot 19$ & $4 \cdot 31$ & $38 \cdot 91$ & $5 \cdot 77$ & -0.59 \\
\hline \multicolumn{6}{|l|}{ Free-Time Activities } \\
\hline Performed & $44 \cdot 89$ & $6 \cdot 79$ & $51 \cdot 70$ & $6 \cdot 11$ & $-13 \cdot 76^{\star}$ \\
\hline Expected & $29 \cdot 89$ & $4 \cdot 11$ & $35 \cdot 18$ & $7 \cdot 23$ & $-10 \cdot 01^{\star}$ \\
\hline
\end{tabular}

Note ${ }^{\star}$ denotes significant difference using Bonferoni method $(p<\cdot 0005)$. All t-tests are one-tailed. 


\section{Discussion}

The current results suggest that SCI is associated with spousal ratings of decreased recreation and free-time activities and increased ratings of socially inappropriate behaviour compared to 'normals.' Although they were rated as having better overall adjustment, SCI subjects were rated as participating in fewer social activities than psychiatric patients. The results of this study mirror analyses with closed head injury (CHI) patients (Klonoff et al., 1986; Stambrook et al., 1989). SCI subjects appear similar to moderately injured $\mathrm{CHI}$ patients in their participation in social role activities and engaging in socially inappropriate behaviours, but resemble severe $\mathrm{CHI}$ patients in their participation in free-time and recreational activities.

While these comparisons were somewhat crude, as simplistic statistical techniques and available normative and psychiatric samples were used, they are generally consistent with other SCI research. Urey and Henggler (1987) noted that spouses in dissatisfied SCI marriages performed fewer activities with their SCI partner and desired the greatest degree of change in their partner's behaviour. Similarly, McGowan and Roth's (1987) research indicated the behaviour control was seen as a problem by the significant other, however, they did find that role delineation was also a concern. Clearly, although several recent studies have shown that many SCI individuals enjoy a positive marital relationship (Crewe et al., 1979; Crewe and Krause, 1988; Deyóe, 1979; Jenik et al., 1982; Pinkerton and Griffin, 1983; Urey and Henggler, 1987; Webb et al., 1982), SCI spouses may experience considerable stress in terms of dealing with their unmet expectations and a partner who acts inappropriately -in social situations.

This study has clear implications for counselling families of SCI patients. SCI patients may require specific intervention to modify what their spouses consider to be socially inappropriate behaviours, although it is important to note that these problems are not as severe as those seen in psychiatric patients. Spouses should be included in this process as they may have to deal with these behaviours on a daily basis and, as well, their perceptions may need to be challenged and possibly recalibrated. Also important is the disparity between the spouses' expectations and the actual performance of free-time activities. This problem has been mentioned before in the context of SCI marriages (Crewe and Krause, 1988; Urey and Henggler, 1987). The frustration of these unmet expectations may be decreased by more realistic expectations, as well as practical suggestions about participation in recreational activities, including the problem of overcoming practical and physical barriers.

During the rehabilitation programme, these issues may have to be specifically addressed to assist in ensuring that families cope maximally with the behavioural and social consequences of SCI. In most hospital rehabilitation programmes, patients participate in recreational activities with other patients rather than with family members. If rehabilitation programmes encouraged spouses to take part in these programmes, the SCI patient would more likely continue activities after discharge. Indeed, research has indicated that including families in the programme may have many other positive effects (Pachalski and Pachalksa, 1984). By addressing the spouse's concerns, it may be possible to modify the SCI patient's adjustment, and hence, the effectiveness of the rehabilitation programme and quality of marital adjustment following hospital discharge. 


\section{References}

Barnes GE, Weinstein CL, Delaney GA, Dubo HCI 1987 Symptoms of depression and spinal cord injury. Report prepared for National Health and Research and Development Program, Ottawa, Canada.

BRACKEN MB, SHEPARD MJ 1980 Coping and adaptation following acute spinal injury: a theoretical analysis. Paraplegia 18:74-85.

Cook DW 1979 Psychological adjustment to SCI: incidence of denial, depression, and anxiety. Rehabilitation Psychology 26:97-104.

Crewe NM, Althelstan GT, Krumberger J 1979 Spinal cord injury: A comparison of preinjury and postinjury marriages. Archives of Physical Medicine and Rehabilitation 60:252-256.

CREWE NM, KRAUS JS 1988 Marital relationships and spinal cord injury. Archives of Physical Medicine and Rehabilitation 69:435-438.

DeJong G, BRANCH LG, CoRCORAN PJ 1984 Independent living outcomes in spinal cord injury: multivariate analysis. Archives of Physical Medicine and Rehabilitation 65:66-73.

DEYOE FS 1979 Marital and family relations following spinal cord injury. Archives of Physical Medicine and Rehabilitation 60:542.

ERNST FA 1987 Contrasting perceptions of distress by research personnel and their spinal cord injured subjects. American fournal of Physical Medicine 66:

HogarTy GE, KaTZ MD 1971 Norms of adjustment and social behavior. Archives of General Psychiatry 25:470-480.

JENIK F, KUHN W, ZACH GA 1982 Social and vocational reintegration of paraplegic and tetraplegic patients in Switzerland. Paraplegia 20:65-70.

KLONOFF PS, COSTA DD, SNOW WG 1986 Predictors and indicators of quality of life in patients with closed head injury. Fournal of Clinical and Experimental Neuropsychology 8:469-485.

MACKELPRANG RW, HEPWORTH DH 1987 Ecological factors in rehabilitation of patients with severe spinal cord injuries. Social Work Health Care 13:23-38.

MacKenzie EJ, Shapiro S, Siegal JH, Moody M, Pitt A 1987 Factors influencing return to work following hospitalization for traumatic injury. American fournal of Public Health 77:329-334.

MALEC J, NERMEYER R 1982 Inpatient spinal cord injury rehabilitation and performance of self-care. Archives of Physical Medicine and Rehabilitation 64:359-363.

McGowaN MB, ROTH S 1987 Family functioning and functional independence in spinal cord injury adjustment. Paraplegia 25:357-365.

PAChAlSKi A, PACHALSKa MM 1984 Programme of active education in the psycho-social integration of paraplegics. Paraplegia 22:238-243.

PINKERTON AC, GRIFFIN ML 1983 Rehabilitation outcomes in females with spinal cord injury: a followup study. Paraplegia 21:166-175.

RICHARDS JS 1986 Psychologic adjustment to spinal cord injury during first postdischarge year. Archives of Physical Medicine and Rehabilitation 67:362-365.

Stambrook M, Moore AD, Peters LC 1989 Social behavior and adjustment to moderate and severe traumatic brain injury: comparison to normative and psychiatric samples. [Abstract]. Fournal of Clinical and Experimental Neuropsychology 11:59.

UREY JR, HENGgLER SW 1987 Marital adjustment following spinal cord injury. Archives of Physical Medicine and Rehabilitation 68:69-74.

WebB SB, LORENZi E, BERZins E 1982 Marital, educational, employment, income and general financial status prior to and one to six years post-spinal cord injury. Paraplegia 20:108-109.

WoODBURY B 1978 Psychological adjustment to spinal cord injury: literature review, 1950-1977. Rehabilitation Psychology 25:119-134. 